\title{
Electrochemistry of potentially bioreductive alkylating quinones
}

\section{Part 1. Electrochemical properties of relatively simple quinones, as model compounds of mitomycin- and aziridinylquinone-type antitumour agents}

\author{
R.J DRIEBERGEN *a, J DEN HARTIGH ${ }^{b}$, J.J.M HOLTHUIS ${ }^{a}$, A HULSHOFF $^{c}$ and W J VAN OORT ${ }^{d}$ \\ Department of Chemical Pharmacy, University of Utrecht, Catharijnesingel 60, 3511 GH Utrecht (The Netherlands)
}

\author{
S J POSTMA KELDER, W. VERBOOM, D N REINHOUDT, M BOS and W E VAN DER LINDEN \\ Department of Chemical Technology, University of Twente, PO Box 217, 7500 AE Enschede (The Netherlands)
}

(Recelved 24th August 1989)

\begin{abstract}
The influence of methyl-, hydroxy and amino substituents on the electrochemical behaviour of simple 1,4-naphthoand 1,4-benzoquinones, model compounds of many quinoıd antitumour agents, in aqueous media was studied Significant changes in electrochemical behaviour were observed, potentially the result of a change in the electron density of the quinone moiety, pre- or post-protonation of substituents, hydrogen bond formation, tautomerization reactions and steric interactions between the quinone moiety and substituents. The information obtained was of benefit in the elucidation of the reduction mechanisms of quinoid antitumour agents such as azindinylquinones and mitomycins
\end{abstract}

Many well-known anticancer agents, such as the anthracyclines (doxorubicin), the mitomycins (mitomycin C) and the aziridinylquinones (carboquone and trenimon), have a quinone funct1on, whereas mitoxantrone, AZQ and BZQ are more recently developed quinoid agents, currently in phase I and II clinical trials (Fig. 1).

a Present address EuroCetus BV, P O Box 23023, 1100 DM Amsterdam, The Netherlands

b Present address Department of Clinical Pharmacy and Toxicology, Unıversity Hospital, Rijnsburgerweg 11, 2333 AA Leiden, The Netherlands

c Deceased 31st May 1986

d Present address Licentec, Churchilllaan 11, 3527 GV Utrecht, The Netherlands
The mechanism(s) of action of quinoid antitumour agents have been thoroughly investigated. The presence of a quinone function offers the possibility of bioreductive activation. Under aerobic conditions, i.e., in organs with sufficient blood supply, a one-electron reduction predominates, resulting in free-radical intermediates such as the toxic superoxide and/or hydroxyl radicals (F1g. 2) [1,2]. This can cause additional damage to the DNA of the tumour cell (strand breakage), but frequently it also induces unwanted damage to the DNA of the normal cells, leading to serious side-effects of the drug. An alternative pathway of activation of substituted quinord compounds involves a two-electron reduction of the quinone function, which may be followed by in- 
<smiles>O=C1c2cccc(O)c2C(=O)c2c(O)c3c(c(O)c21)CC(O)(C(=O)CO)CC3OS</smiles>

(a)

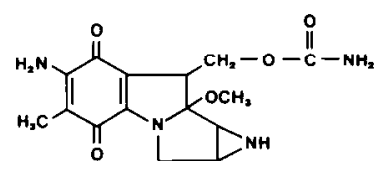

(b)

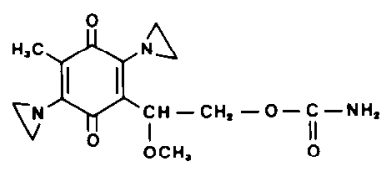

(c)<smiles></smiles>

(d)

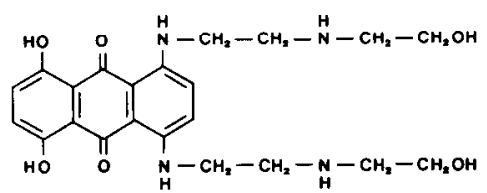

(e)

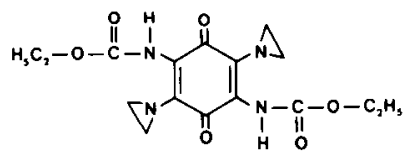

(f)

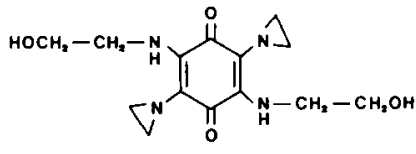

(g)

F1g 1 Structures of (a) doxorubicin ( $\mathrm{S}=$ amino sugar molety), (b) mitomycin $\mathrm{C}$, (c) carboquone, (d) trenımon, (e) mitoxantrone, (f) AZQ and (g) BZQ

activation through subsequent glucuronidation and/or sulphation (Fig. 2) or by the conversion of the hydroquinone into an alkylating intermediate, the quinone methide (Fig. 3). Such a pattern is believed to predominate under anaerobic conditions which are assumed to exist in cells of solid tumours where the blood supply is in general poor $[3,4]$. A second alkylating centre can also be present in the quinone, e.g., when $R_{1}, R_{2}$ or $R_{3}$ (Fig. 3) also contains a $-\mathrm{CH}_{2} \mathrm{X}$ moiety $(\mathrm{X}=$ leaving group). In that case, cross-linking of the nucleophile (i.e., DNA) can occur.
A number of data support this so-called bioreductive alkylation concept of quinoid antitumour agents [5,6 and references cited therein]. However, there is some controversy in the literature about the oxidation state of the alkylating species. Nevertheless, the electrochemical properties of the compound are very important for its bioreductive activation, either to the semiquinone radical or to the hydroquinone. It can be hypothesized that when relatively large conjugated aromatic systems are involved (e.g., substituted naphtho- and anthraquinones, mitosenes), reduction of the

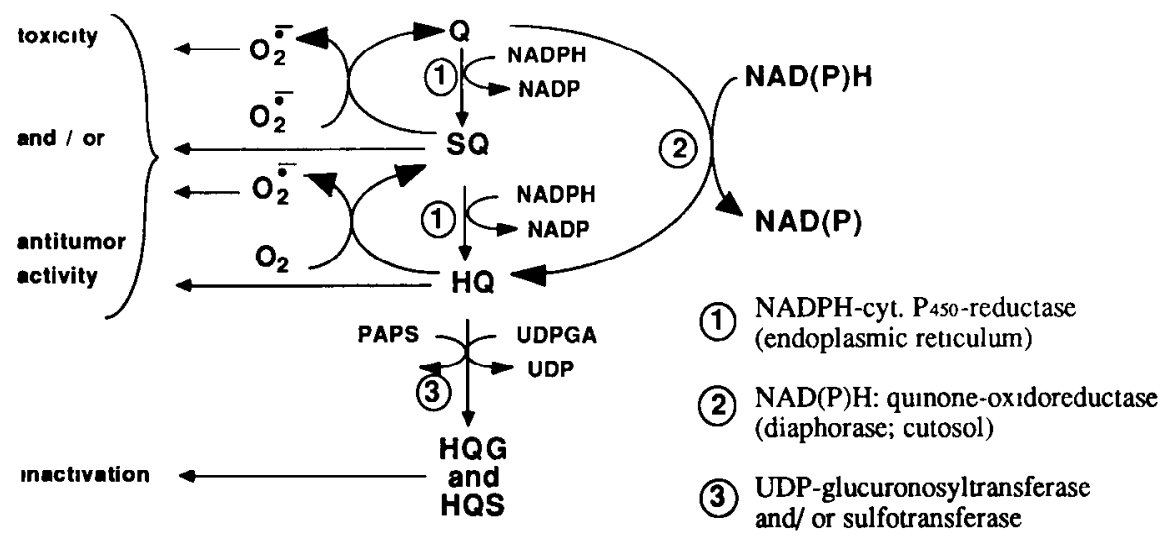

Fig 2 Enzymatic reduction pathways of quinone-containıng anticancer agents (Q) to semiquinone free radicals (SQ) and hydroquinones (HQ), inactivation of the hydroquinone by sulphation (S) and glucuronidation (G) and, under aerobic conditions, generation of activated oxygen species 


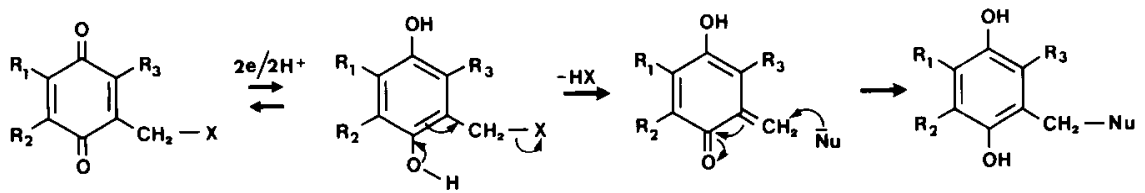

Fig 3 Two-electron reduction and, under anaerobic conditions, subsequent formation of an alkylatıng species by chemical conversion of the reduction product $\mathrm{X}=$ Leaving group, $\mathrm{Nu}=$ nucleophile.

quinone function may be the limiting step for antitumour activity through alkylation, as it may be too difficult to take place. However, systemic toxicity caused by free-radical formation may also be much lower, as has been found for the anthracenediones and a series of anthrapyrazole derivatives $[7,8]$.

Both the reduction step and the subsequent elimination step are strongly influenced by the substituents attached to the quinone function: electron-withdrawing substituents facilitate reduction, but subsequent elimination of leaving group $\mathrm{X}$ will be more difficult. Electron-donating substituents facilitate the latter step and hinder the reduction step. Hence quinone substituents influence both steps in an opposite way and an optimum substitution pattern is required for maximum efficacy of the activation reactions. Further, the electronic properties of group $X$, preferably being a good leaving group, are also important.

Electrochemical studies offer the possibility of examining the ease of the reduction step and the influence of variations in the molecular structure of the compound on parameters characteristic of the reduction process. This implies that biological processes (both in vitro and in vivo) in which reduction processes are involved (activity and toxicity) may be related to these electrochemical parameters. The successful use of electrochemical parameters in the development of new analogues has been reported, for instance in the design of new sulpha drugs [9] and radiosensitizing agents of the nitroaromatic type, which release their activity after a reductive activation process [10]. Structure-activity relationships in this class of compounds, using electrochemical parameters, enabled predictions to be made of chemical and biochemical interactions of new, rationally designed derivatives.
Relationships between the electrochemical properties of the compound and biological, cytostatic activity of bioreductive alkylating quinones have been studied mostly using only the half-wave potential $\left(E_{1 / 2}\right)$ of the quinone reduction step (e.g., of the mitomycins [11-14]). Generally, poor correlations were found, which may have been influenced by a lack of knowledge about the electrochemical behaviour of the compound and its relationshıp to the complex mode of action. Because the redox or half-wave potential only describes the first step of the activation mechanısm, no information about the second step, the formation of the actual alkylating intermediate, is taken into account in these studres. However, this second step can also be examined, viz., by investigating the (electro)chemical stability of the reduction product. Consequently, electrochemical analysis may be a valuable tool in the search for new bioreductive alkylating quinones if their general mechanism of reduction is of the ECE type, where an electrochemical process (E) is followed by a rate-determining chemical reaction $(\mathrm{C})$, its product(s) being electroactive and detected in a second electrochemical process $(\mathrm{E})$. The reduction mechanısms of the aziridinylquinones and the mitomycins have been identified as ECE mechanisms $[5,6,15]$. The complexity of such electrode processes, however, requires the elucidation of the reduction mechanisms, before substituent effects can be examined in detail [16]. Once elucidated, parameters describing both the quinone reduction step and the subsequent formation of the alkylating species can be derived and used in structureactivity relationship studies [6]. Thus, electrochemical analysis of a series of compounds, followed by quantitative structure-electrochemistry, structure-antitumour actıvity and structure-toxicity relationships, may yield valuable information for 
the design of more potent, less toxic analogues.

This study was aimed at the determination of the electrochemical properties of quinoid antitumour agents and the possible correlation of parameters derived from these properties with the in vitro and in vivo cytotoxicity of these compounds. The mitomycins and the azıridinylquinones are two classes of compounds of particular interest, because their mechanisms of action may proceed via the bioreductive activation mechanisms described above, and new analogues, carrying "tailor-made" substituents, can be synthesized. In order to obtain more insight into the reduction mechanism of complex quinones, it is essential to study a number of simple quinones as model compounds. Investigation of such compounds will allow the individual acid-base reactions to be separated and the role of individual substituents to be distinguished, provided that standardized conditions are used. In reports of most studies on the electrochemistry of these simple quinones in aqueous media, however, only fragmentary data are available on a limited number of compounds in a narrow $\mathrm{pH}$ range. Comparison and correlation of the published data are hardly possible because of the wide variety of experimental conditions used. The aim of this study was to examine the reduction mechanism of a series of quinones under standard conditions, i.e., at a dropping mercury electrode (DME), in aqueous media and over a wide $\mathrm{pH}$ range.

In the first paper of this series, some electrochemical properties of a selected group of quinones, as model compounds of mitomycin- and aziridınylquinone-type antitumour agents, are reported.

\section{TABLE 1}

Structures of simple model compounds

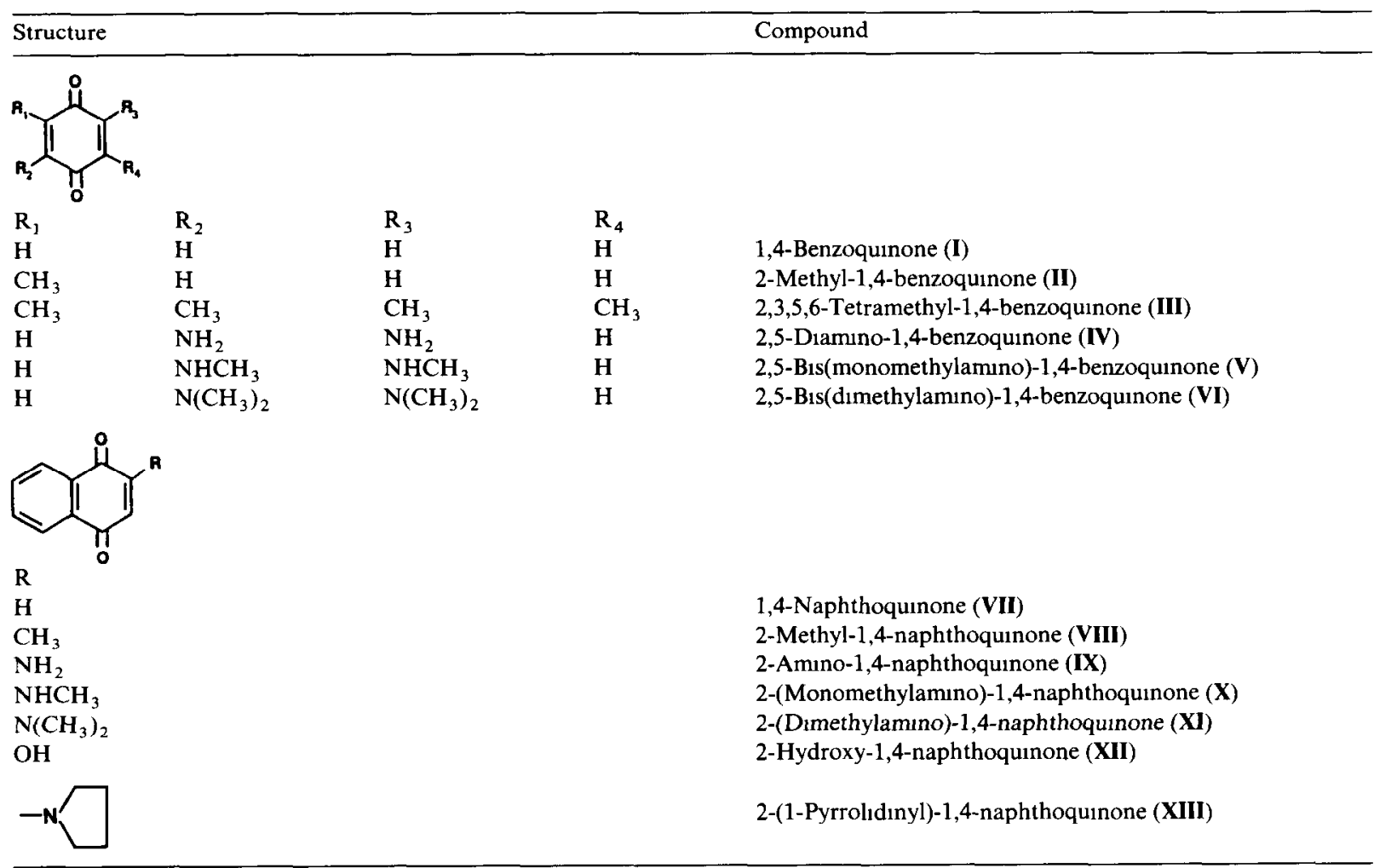




\section{EXPERIMENTAL}

\section{Chemicals}

The structures of the compounds studied are presented in Table 1. 1,4-Benzoquinone (I), 2,3,5,6-tetramethyl-1,4-benzoquinone (III), 1,4naphthoquinone (VII), 2-methyl-1,4-naphthoquinone (VIII) and 2-hydroxy-1,4-naphthoquinone (XII) were obtained from Aldrich Europe (Janssen Chimica, Beerse, Belgium) and 2-methyl-1,4benzoquinone (II) from Merck (Darmstadt, F.R.G.), and were used without further purification. 2,5-Diamino-1,4-benzoquinone (IV) [17], 2,5b1s(monomethylamino)-1,4-benzoquinone (V) [18], 2,5-bis(dimethylamino)-1,4-benzoquinone (VI) [19], 2-amino-1,4-naphthoquinone (IX), 2-(monomethylamino)-1,4-naphthoquinone $(\mathbf{X})$ and 2-(dimethylamino)-1,4-naphthoquinone (XI) [20,21] and 2-(1-pyrrolidinyl)-1,4-naphthoquinone (XIII) [22] were prepared as described.

Stock solutions $(0.01 \mathrm{M})$ of these quinones were prepared by disolution in methanol (zur Analyse, Merck) and stored at $4{ }^{\circ} \mathrm{C}$. The composition of the buffers used has been reported before [6]. Chemicals used for the preparation of the buffers were of analytical-reagent grade (Merck).

\section{Apparatus}

The polarograms were recorded on a Bruker E310 modular electrochemical system, equipped with a drop tımer and a Houston 2000 or a Kipp BD $90 x-y$ recorder. A water-jacketed 10-ml polarographic cell (Metrohm EA 880-T-5) with a dropping mercury electrode, a Metrohm EA 436 $\mathrm{Ag} / \mathrm{AgCl} / 3 \mathrm{M} \mathrm{KCl}$ reference electrode and a platinum wire auxiliary electrode was employed. The cell was kept at $20^{\circ} \mathrm{C}$. The $\mathrm{pH}$ values were measured with a Radiometer PHM-64 research pH meter, equipped with an Ingold LOT-401 combined glass/reference electrode.

\section{Procedures}

Direct current (d.c.) polarograms were all recorded at a scan rate of $2 \mathrm{mV} \mathrm{s}{ }^{-1}$ and with a drop time of $2 \mathrm{~s}$. For recording the polarograms a general procedure was used. The buffer solution ( $\mu=0.1 \mathrm{M} ; 10.0 \mathrm{ml}$ ) was deaerated by bubbling oxygen-free nitrogen through it [23] and the current-voltage curve was recorded (blank). Then $100 \mu \mathrm{l}$ of the freshly prepared stock solution of the quinone were added and the polarographic curve of the resulting solution, with a final concentration of the quinone of $0.1 \mathrm{mM}$, was recorded again, after an additional deaeration for 1 min. The starting potential was fixed during the recording of a complete $E_{1 / 2}-\mathrm{pH}$ diagram. However, if degradation of the parent compound was observed on repeated polarographic scans of the same solution, a new curve was recorded with a fresh sample solution of that particular compound. This time the starting potential was selected just in front of the wave of the parent compound, so as to achieve a more accurate determination of the half-wave potential. Sometimes the temperature of the cell was decreased to $4^{\circ} \mathrm{C}$ in order to retard the chemical decomposition process.

The measurement of half-wave potentials can be affected by differences in the potential of the reference electrode. To eliminate this influence the thalluum reduction wave was used as a reference value. The half-wave potential of the thallium reduction wave was determined daily under the same experimental conditions $\left(E_{1 / 2}=-0.455 \mathrm{~V}\right)$ and all the other data obtained were corrected for day-to-day variations, if necessary [16]. For some compounds the type of the observed polarograms was characterized, e.g., by cyclic voltammetry on a hanging mercury drop electrode, by logarithmic analysis of the recorded d.c. wave or by studying the influence of the mercury pressure, the temperature and/or the concentration of the quinone on the d.c. polarogram [24].

The number of electrons transferred in a particular reduction step $(n)$ was determined as follows. At pH 7.0 or 8.0 (phosphate buffer) the wave heights of all quinones studied were compared with those of equimolar solutions of benzophenone, 1,4-benzoquinone and 1,4-naphthoquinone, which are known to be reduced in a two-electron step [25]. If the experimental cond1tions (type of solvent, temperature, mercury pressure, etc.) are kept constant, and if the polarographic waves are diffusion controlled, then the $n_{1}$ value of the compound under investigation can be calculated from the known $n_{2}$ value of another 
compound by means of the equation

$n_{1}=n_{2} \cdot \frac{\left(i_{\mathrm{d}} M^{1 / 6}\right)_{1}}{\left(i_{\mathrm{d}} M^{1 / 6}\right)_{2}}$

where $M$ is the molecular weight of the compounds [26].

\section{RESULTS}

All compounds investigated showed qualitatively similar electrochemical behaviour (Figs. 4 and 5; Table 2), which can be considered in general as follows.
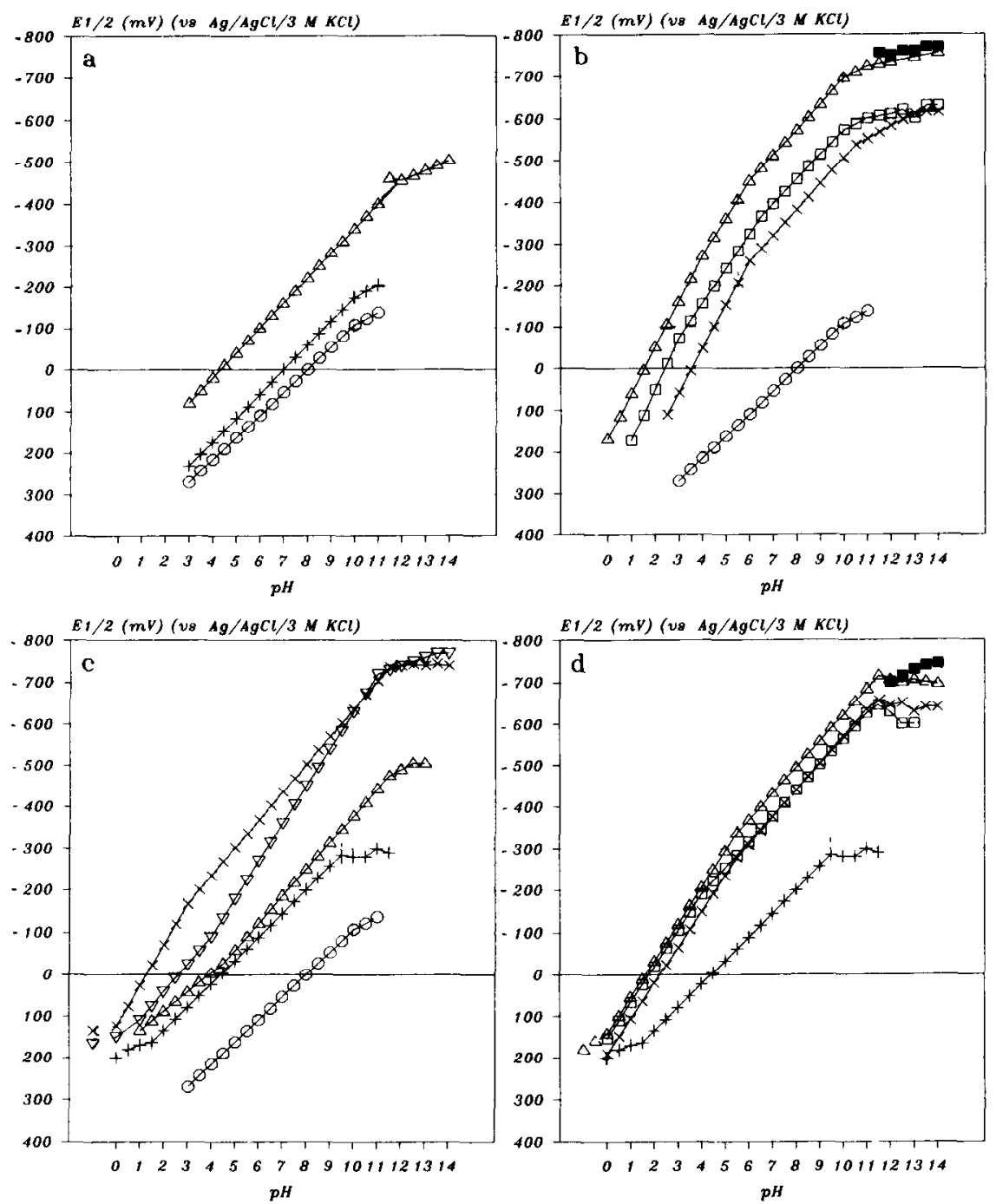

Fig. 4. Dependence of half-wave potentials $\left(E_{1 / 2}\right)$ on $\mathrm{pH}$ for the reduction waves of the parent compound of (a) (O) 1,4-benzoquinone (I), (+ ) 2-methyl-1,4-benzoquinone (II) and $(\Delta)$ 2,3,5,6-tetramethyl-1,4-benzoquinone (III); (b) (O) 1,4-benzoquinone (I), ( $\square$ ) 2,5-diamıno-1,4-benzoquinone (IV), ( $\Delta$ ) 2,5-bıs(monomethylamıno)-1,4-benzoquinone (V), ( $\times$ ) 2,5-bis(dımethylamıno)-1,4-benzoquinone (VI) and ( $\square$ ) of the reduction of a decomposition product of IV, (c) (O) 1,4-benzoquinone (I), ( $)$ 1,4-naphthoquinone (VII), $(\Delta)$ 2-methyl-1,4-naphthoquinone (VIII), ( $\nabla)$ 2-hydroxy-1,4-naphthoquinone (XII) and (X) 2-(1-pyrrolidinyl)-1,4-naphthoquinone (XIII), (d) (+) 1,4-naphthoquinone (VII), (ㅁ) 2-amino-1,4-naphthoquinone (IX), ( $\Delta$ ) 2-(monomethylamino)-1,4-naphthoquinone (X), (X) 2-(dimethylamıno)-1,4-naphthoquinone (XI) and $(\square)$ of the reduction wave of a decomposition product of IX 

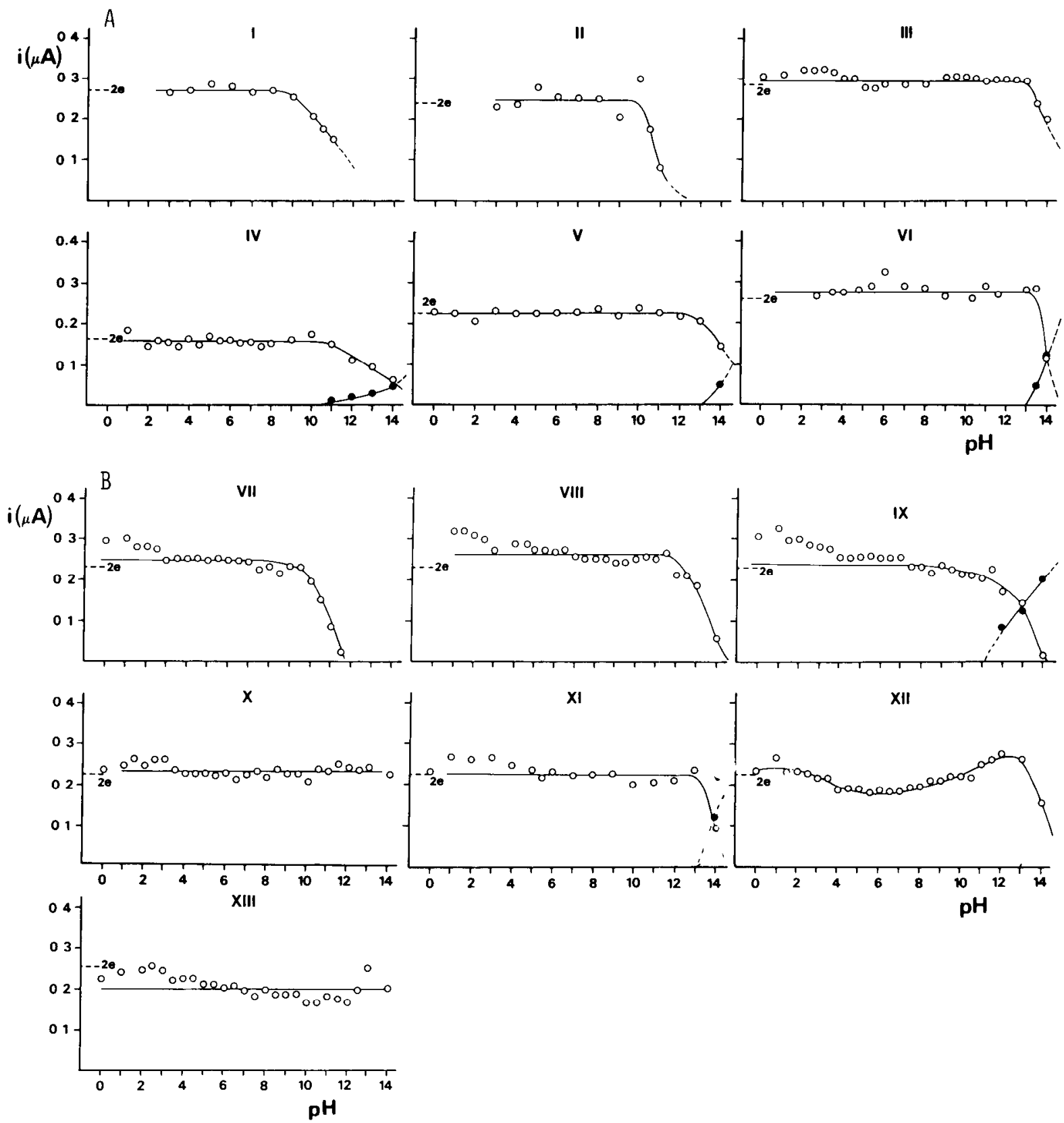

Fig 5. Dependence of limiting current ( 1 ) on $\mathrm{pH}$ for the reduction waves of the parent compound (O) of (A) 1,4-henzoquinone (I), 2-methyl-1,4-benzoquinone (II), 2,3,5,6-tetramethyl-1,4-benzoquinone (III), 2,5-diamuno-1,4-benzoquinone (IV), 2,5-bis(monomethylamino)-1,4-benzoquinone (V), 2,5-bis(dımethylamino)-1,4-benzoquinone (VI) and (•) of decomposition products of IV, V and VI, (B) 1,4-naphthoquinone (VII), 2-methyl-1,4-naphthoquinone (VIII), 2-amino-1,4-naphthoquinone (IX), 2-(monomethylamino)-1,4-naphthoquinone (X), 2-(dımethylamıno)-1,4-naphthoquinone (XI), 2-hydroxy-1,4-naphthoquinone (XII), 2-(1-pyrrolidınyl)-1,4-naphthoquinone (XIII) and (•) of decomposition products of IX and XI. 
TABLE 2

Results of polarographıc analysıs of $\mathbf{I}-\mathbf{X I I I}$

\begin{tabular}{|c|c|c|c|c|c|c|}
\hline $\mathrm{Cpd}^{\mathrm{d}}$ & $\mathrm{pH}^{\mathrm{b}}$ & $\mathrm{d} E_{1 / 2} / \mathrm{dpH}^{\mathrm{c}}$ & at $\mathrm{pH}$ & $n^{d}$ & $E_{1 / 2}{ }^{\mathrm{e}}$ & Decomp $^{f-1}$ \\
\hline I & $3-11$ & 54 & $3-10$ & 20 & +55 & At $\mathrm{pH}>9$ \\
\hline II & $3-11$ & 58 & $3-10$ & 2.1 & 0 & ${ }^{\mathrm{f}}$ At $\mathrm{pH}>10$ \\
\hline III & $-1-14$ & 60 & $3-12$ & 2.0 & -160 & ${ }^{\mathrm{g}}$ At $\mathrm{pH}>13$ \\
\hline \multirow[t]{3}{*}{ IV } & $1-11$ & 59 & $65-10$ & 1.9 & -395 & ${ }^{\mathrm{h}}$ At $\mathrm{pH}>11$ \\
\hline & & 84 & $<6.5$ & & & \\
\hline & & 119 & $<3$ & & & \\
\hline \multirow[t]{3}{*}{$\mathbf{v}$} & $0-13$ & 61 & $6-10$ & 21 & -511 & ${ }^{\mathrm{h}}$ At $\mathrm{pH}>13$ \\
\hline & & 90 & $4-6$ & & & \\
\hline & & 110 & $<4$ & & & \\
\hline \multirow[t]{2}{*}{ VI } & $1-14$ & 62 & $6-105$ & 22 & -319 & ${ }^{\mathrm{h}}$ At $\mathrm{pH}>13$ \\
\hline & & 105 & $<6$ & & & \\
\hline VII & $0-12$ & 56 & $15-95$ & 20 & -145 & At $\mathrm{pH}>9$ \\
\hline VIII & $1-13$ & 64 & $45-115$ & 21 & -186 & ${ }^{\mathrm{f}}$ At $\mathrm{pH}>13$ \\
\hline \multirow[t]{2}{*}{ IX } & $0-13$ & 62 & $4-115$ & 20 & -377 & ${ }^{\prime}$ At $\mathrm{pH}>11$ \\
\hline & & 86 & $<4$ & & & \\
\hline \multirow[t]{2}{*}{$\mathbf{x}$} & $-1-14$ & 63 & $5.5-115$ & 19 & -431 & ${ }^{\prime}$ At $\mathrm{pH}>13$ \\
\hline & & 87 & $<55$ & & & \\
\hline \multirow[t]{2}{*}{ XI } & $0-14$ & 65 & $5.5-115$ & 20 & -374 & ${ }^{\prime}$ At $\mathrm{pH}>13$ \\
\hline & & 85 & $<55$ & & & \\
\hline \multirow[t]{2}{*}{ XII } & $-1-14$ & 66 & $1-4$ & 18 & -360 & - \\
\hline & & 90 & $4-11$ & & & \\
\hline \multirow[t]{2}{*}{ XIII } & $-1-14$ & 67 & $3-11.5$ & 16 & -435 & ${ }^{1}$ At $\mathrm{pH}>13$ \\
\hline & & 97 & $<3$ & & & \\
\hline
\end{tabular}

${ }^{a}$ For structures see Table $I^{b}{ }^{b}$ Limited by the oxidation of mercury and the chemical stability of the compound ${ }^{c}$ Slope (mV pH ${ }^{-1}$ ) of $E_{1 / 2}-\mathrm{pH}$ plot in the $\mathrm{pH}$ range given ${ }^{\mathrm{d}}$ Number of electrons of the parent reduction wave at $\mathrm{pH} 70^{\mathrm{c}}$ Half-wave potential ( $E_{1 / 2}$, $\mathrm{mV}$ ) of the parent reduction wave at $\mathrm{pH} 70^{\mathrm{f}}$ Appearance of several small reduction and oxidation waves in the polarographic curves, the total current decreasıng ${ }^{\mathrm{g}} \mathrm{As} \mathrm{g}$, but after a longer period of tıme ${ }^{\mathrm{h}}$ Time-dependent, gradual replacement under alkaline conditions of the parent reduction wave by two and, finally, one new reduction wave, the total current remaining at the original value of the parent wave. 'Time-dependent replacement under alkalıne conditions of the parent reduction wave by one new reduction wave, the total current remaining at the onginal value of the parent wave

The compounds were studied in a $\mathrm{pH}$ range that was as large as possible. In acidic media polarographic analysis is limited by the interference of oxidation of mercury, whereas at $\mathrm{pH}>9$ decomposition of the quinone of interest frequently occurs, which makes polarographic analysis impossible.

Generally, one well developed reduction wave can be observed, corresponding with a two-electron reduction process. Slightly higher currents were obtained in sulphuric acid solutions. This wave is diffusion controlled, as was verified by variation of the concentration of the compound, mercury pressure, etc. New, small reduction and oxıdation waves can be observed during polarographic analysis of I, II, VII and VIII under alkalıne conditions, while both the parent wave and the total current decrease. Repetitive polarographic analysis of the same solution of these quinones reveals a time-dependent decrease of the parent wave. Repetitive polarographic analysis of IV, $\mathbf{V}$ and $\mathbf{V I}$ and of IX, $X$ and XI shows that the parent reduction wave is gradually replaced in time initıally by two (IV, V and VI) and finally by one new reduction wave (all six compounds), whereas the total current [parent wave + new wave(s)] remains at the original height of the parent wave.

All compounds reveal a small pre-wave, just in front of the parent reduction wave, in the entire $\mathrm{pH}$ range studied. In addition, the polarographic waves show a smaller slope when recorded under alkaline conditions.

A slope in the $E_{1 / 2}-\mathrm{pH}$ plot of ca. $60 \mathrm{mV}$ 
$\mathrm{pH}^{-1}$ can be observed in the medium $\mathrm{pH}$ range for virtually all compounds, with the exception of quinone XII, which shows a slope of $90 \mathrm{mV} \mathrm{pH}^{-1}$ at $\mathrm{pH}>4$. An increase in the slope to ca. $90 \mathrm{mV}$ $\mathrm{pH}^{-1}$ with decrease in $\mathrm{pH}$ can be observed in the plots of the aminoquinones (IV, V and VI, and IX, X, XI and XIII). Quinones IV, V and VI also show a part with a slope of $105-120 \mathrm{mV} \mathrm{pH}^{-1}$ and XIV of $75 \mathrm{mV} \mathrm{pH}{ }^{-1}$. A decrease in the slope can be observed at alkaline $\mathrm{pH}$. The half-wave potentials of the new waves formed during polarographic analysis under alkaline conditions of $\mathbf{I V}, \mathbf{V}$ and VI, and IX, $\mathbf{X}$ and $\mathbf{X I}$ are virtually independent of $\mathrm{pH}$.

\section{DISCUSSION}

The quinones examined are derivatives of 1,4benzoquinone and 1,4-naphthoquinone. It $1 \mathrm{~s} 1 \mathrm{~m}$ portant to understand the electrochemical behaviour of these two compounds, in order to be able to interpret that of more complex derivatives such as mitomycin $\mathrm{C}$ and $\mathrm{AZQ}$ properly. The literature shows different interpretations of the electrochemical behaviour of compounds having a quinone function [16,27-29]. Therefore, some general remarks about quinone electrochemistry in aqueous media, which is necessary for an adequate interpretation of the results, will be made first.

\section{General mechanism of reduction}

In general, reduction of a quinone function $Q$ can be represented by a $3 \times 3$ array of reactants, intermediates and products which are interrelated by electron and proton transfer steps (Scheme 1). Which of the possible electrochemical pathways will be followed in a particular case depends on the compound studied, the type of electrode and the solvent used. In aqueous solvents, the mechanism of the electrode reaction depends strongly on the $\mathrm{pH}$ of the solution and the $\mathrm{p} K_{\mathrm{a}}$ values of the acid-base functions of the quinone $Q$, the semiquinone radical $\mathrm{SQ}$ and the hydroquinone $\mathrm{HQ}$ (Scheme 1). Various possible reaction pathways in Scheme 1 have been proposed by different workers [16,27-29]. However, a detailed study of the electrode kinetıcs of a quinone couple at a dropping

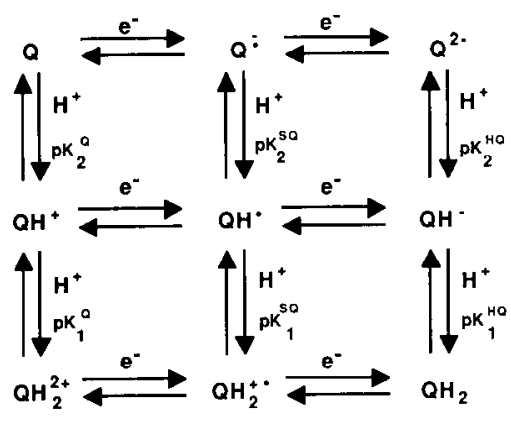

Scheme 1 General scheme of reduction of quinones, represented by a $3 \times 3$ array of quinones (Q), one-electron reduction products (semiquinone radicals, e $\mathrm{g}, \mathrm{QH}^{*}$ ) and two-electron reduction products (e g, the hydroquinone $\mathrm{QH}_{2}$ ), in different states of protonation

mercury electrode in aqueous solutions has not yet been published. The kinetics of the 1,4-benzoquinone-hydroquinone couple on a platinum electrode were analysed by Laviron [29] and reviewed by Chambers [27]. Experimental data from the literature (e.g., $\mathrm{p} K_{\mathrm{a}}$ values of the oxıdized and reduced species) were examined with respect to the ninc-member square scheme where all protonation reactions are assumed to be at thermodynamic equilibrium. The results indicated that between $\mathrm{pH} 0$ and 7 the protonations in the $p$-benzoquinone-hydroquinone systems are fast, whereas the electrochemical reactions are rate controlling. Between $\mathrm{pH} 0$ and 7 the main reaction sequence during the reduction was hypothesized to be successively $\mathrm{HeHe}$, eHHe and $\mathrm{eHeH}$, with the reverse order for the oxidation. As the transitions between the different sequences did not correspond to any change in the slope of the $E_{1 / 2}-\mathrm{pH}$ diagram, it was concluded that the reaction scheme cannot be solely determined from the variations of $E_{1 / 2}$ with $\mathrm{pH}$.

However, taking into account the $\mathrm{p} K_{\mathrm{a}}$ values of $\mathrm{Q}, \mathrm{SQ}$ and $\mathrm{HQ}$ (Scheme 1), a sequence of proton and electron uptake can be assumed. It is clear that the transition points in the reduction mechanism depend on the $\mathrm{p} K_{\mathrm{a}}$ values of the individual oxidized and reduced species involved in the total electrode process, so $\mathrm{p} K_{1}^{\mathrm{Q}}, \mathrm{p} K_{2}^{\mathrm{Q}}, \mathrm{p} K_{1}^{\mathrm{SQ}}$, $\mathrm{p} K_{2}^{\mathrm{SQ}}, \mathrm{p} K_{1}^{\mathrm{HQ}}$ and $\mathrm{p} K_{2}^{\mathrm{HQ}}$. The exact sequence of proton and electron uptake cannot be easily determined from polarographic data, but a sim- 
plified mechanism for the reduction of a simple quinone such as 1,4-benzoquinone or 1,4-naphthoquinone can be adapted, based on the $\mathrm{p} K_{\mathrm{a}}$ values mentioned above and on the assumption that reactions at the electrode are governed solely by the true $\mathrm{p} K_{\mathrm{a}}$ values of the carbonyl groups and
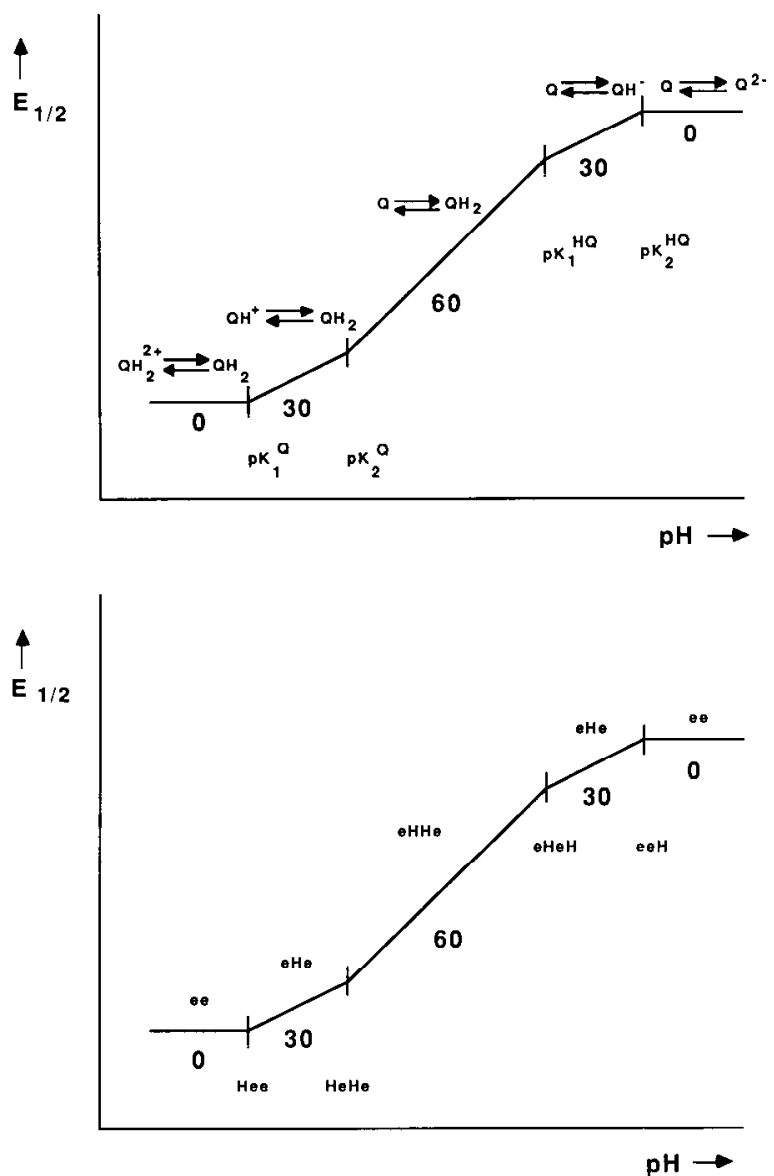

Fig. 6 Hypothetical $E_{1 / 2}-\mathrm{pH}$ plots for the two-electron reduction wave of simple quinones in aqueous media. Inflection points at acidic $\mathrm{pH}$ correspond to the $\mathrm{p} K_{\mathrm{a}}$ values of the quinone morety and those at alkaline $\mathrm{pH}$ to the $\mathrm{p} K_{\mathrm{a}}$ values of the hydroquinone It is assumed that no other acid-base equilibria (e.g., of substituents) take place and, in the lower plot, that protonation/deprotonation reactions of the quinone-hydroquinone couple are not influenced by interactions between electrode and compound In that case reduction mechanisms can be hypothesized to be ee, eHe, eHHe, eHe and ee with increasing $\mathrm{pH}$, with slopes in the plot of $0,30,60$, 30 and $0 \mathrm{mV} \mathrm{pH}{ }^{-1}$ respectively, and the reverse order for the oxidation In intermediate $\mathrm{pH}$ regions mechanisms such as $\mathrm{Hee}, \mathrm{HeHe}, \mathrm{eHeH}$ and eeH are suggested. the phenolic hydroxyl groups. Hence interactions between mercury and the compound, leading to protonation/deprotonation steps, are excluded. In this simplified model the reduction mechanism of a quinone would be as indicated in Fig. 6, in which only protonation reactions at the electrode are indicated, as they affect the slope of the $E_{1 / 2^{-}}$ $\mathrm{pH}$-plot, whereas those in the bulk of the solution do not. Five parts can be distinguished in Fig. 6 . The sequence of proton and electron uptake for the reduction of a quinone to the hydroquinone in each of these parts can be hypothesized to be as follows (taking into account also the oxidation of the hydroquinone formed to the quinone).

(a) At $\mathrm{pH}<\mathrm{p} K_{1}^{\mathrm{Q}}$ : protonation of the quinone function $\mathrm{Q}$ to $\mathrm{QH}_{2}^{2+}$ in the bulk of the solution, followed by reduction of $\mathrm{QH}_{2}^{2+}$ to $\mathrm{QH}_{2}$ by an ee mechanism. The overall mechanism can be described by $\mathrm{HHee}$, where $H$ represents bulk protonation. The hydroquinone formed $\left(\mathrm{QH}_{2}\right)$ can be oxidized in this $\mathrm{pH}$ range by an ee mechanism to $\mathrm{QH}_{2}^{2+}$, which does not deprotonate at this $\mathrm{pH}$. Since protonation of $\mathrm{Q}$ proceeds in the bulk, variation of the $\mathrm{pH}$ does not affect the slope in the $E_{1 / 2}-\mathrm{pH}$ plot.

(b) When $\mathrm{p} K_{1}^{\mathrm{Q}}<\mathrm{pH}<\mathrm{p} K_{2}^{\mathrm{Q}}$, however, $\mathrm{QH}^{+}$is formed. At increasing $\mathrm{pH}$, one electron may be consumed first, especially considering the positive charge of $\mathrm{QH}^{+}$, leading to the formation of $\mathrm{QH}$ : Since $\mathrm{pH} \ll \mathrm{p} K_{1}^{\mathrm{HQ}}, \mathrm{QH}^{-}$will not be formed, but $\mathrm{QH}^{*}$ will be protonated first to $\mathrm{QH}_{2}^{+*}$, which is then finally reduced to $\mathrm{QH}_{2}$. The overall mechanism can be described by $\mathrm{HeHe}$, i.e., at the electrode an eHe mechanism takes place which results in a slope of $30 \mathrm{mV} \mathrm{pH}{ }^{-1}$ unit in the $E_{1 / 2}-\mathrm{pH}$ plot. In the intermediate pH-range between (a) and (b) $\mathrm{QH}_{2}^{2+}$ may be formed, so the first step in this range may be the uptake of a proton and an $H$ Hee mechanism may occur. Oxidation of the hydroquinone to $\mathrm{QH}^{+}$will start by the release of one electron (not a proton since at $\mathrm{pH} \ll \mathrm{p} K_{1}^{\mathrm{HQ}}$, $\mathrm{QH}^{-}$will not be formed) leading to $\mathrm{QH}^{+}$, followed by deprotonation to $\mathrm{QH}^{*}$ [electron release to $\mathrm{QH}_{2}^{2+}$ only in the intermediate $\mathrm{pH}$ range between (a) and (b)] and the release of the second electron to $\mathrm{QH}^{+}$. Hence an eHe mechanism, and in the intermediate $\mathrm{pH}$ range eeH, is assumed to take place. Both mechanısms are exactly the re- 
verse order of the corresponding reduction mechanisms, which clearly demonstrates the chemical reversibility of the electrode reaction.

(c) At $\mathrm{p} K_{2}^{\mathrm{Q}}<\mathrm{pH}<\mathrm{p} K_{1}^{\mathrm{HQ}}$, the quinone $\mathrm{Q}$ is present as such in the bulk of the solution. The first step of the reduction process in this $\mathrm{pH}$ range will be the uptake of an electron by $Q$ to $Q^{-*}$ (since $\mathrm{pH}>\mathrm{p} K_{2}^{\mathrm{Q}}$ ), followed by the uptake of the first proton to $\mathrm{QH}^{-}$(since $\mathrm{pH} \ll \mathrm{p} K_{2}^{\mathrm{HQ}}$ ) and the second proton to $\mathrm{QH}_{2}^{+*}$ (since $\mathrm{pH}<\mathrm{p} K_{1}^{\mathrm{HQ}}$ ). The mechanism can be represented by eHHe. In the intermediate $\mathrm{pH}$ range between (b) and (c) $\mathrm{QH}^{+}$ may still be formed ( $\mathrm{HeHe}$ ) and in the intermediate $\mathrm{pH}$ range between (c) and (d) $\mathrm{QH}^{-}$may be formed $(\mathrm{eHeH})$. The reverse order of electron and proton uptake can be observed during oxidation of the hydroquinone to the quinone. It will start by the release of an electron to $\mathrm{QH}^{+}$, since at $\mathrm{pH}<\mathrm{p} K_{1}^{\mathrm{HQ}} \mathrm{QH}^{-}$will not be formed [except in the intermediate $\mathrm{pH}$ range between (c) and (d)]. This will be followed by subsequent deprotonation of $\mathrm{QH}_{2}^{+\cdot}$ to $\mathrm{QH}^{*}$ and $\mathrm{Q}^{-\cdot}$, respectively, since in this $\mathrm{pH}$ range neither $\mathrm{QH}_{2}^{2+}$ nor $\mathrm{QH}^{+}$will be formed (eHHe). The latter may, however, be formed in the intermediate $\mathrm{pH}$ range between (b) and (c) $(\mathrm{eHeH})$, whereas in the intermediate $\mathrm{pH}$ range between (c) and (d) an $\mathrm{HeHe}$ oxidation mechanism may proceed. All mechanisms describe the involvement of two electrons and two protons in the electrode reaction. Consequently, a slope of $60 \mathrm{mV} \mathrm{pH}^{-1}$ unit can be expected in the $E_{1 / 2}-\mathrm{pH}$ plot.

(d) $\mathrm{p} K_{1}^{\mathrm{HQ}}<\mathrm{pH}<\mathrm{p} K_{2}^{\mathrm{HQ}}$ : the quinone Q will be reduced to the hydroquinone monoanion $\mathrm{QH}^{-}$in this $\mathrm{pH}$ range. The first step can be hypothesized to be the uptake of an electron by $Q$ to $Q^{- \text {. }}$ ( $\mathrm{pH} \gg \mathrm{p} K_{2}^{\mathrm{Q}}$, so $\mathrm{QH}^{+}$is not formed), followed by protonation to $\mathrm{QH}^{\cdot}\left(\mathrm{pH}<\mathrm{pK}_{2}^{\mathrm{HQ}}\right)$ and reduction to $\mathrm{QH}^{-}(\mathrm{eHe})$, except for the intermediate $\mathrm{pH}$ region between (d) and (e), where formation of the dianion results in an eeH mechanism. A slope of $30 \mathrm{mV} \mathrm{pH}{ }^{-1}$ unit can be expected in the $E_{1 / 2}-\mathrm{pH}$ plot owing to the involvement of two electrons and only one proton in the electrode reaction. By analogy with the mechanisms described above, an eHe mechanism seems to be the predominant path for the oxidation of the hydroquinone monoanion to the quinone in this $\mathrm{pH}$ range. (e) $\mathrm{pH}>\mathrm{p} K_{2}^{\mathrm{HQ}}$ : protonation of neither the quinone nor the reduction products will take place at this $\mathrm{pH}$, so reduction and oxidation proceed through an ee mechanism and, as a consequence, $\mathrm{pH}$ independence of $E_{1 / 2}$ is observed.

In conclusion, only protonation/deprotonation reactions during a reduction/oxidation process at the electrode surface contribute to the slope in the $E_{1 / 2}-\mathrm{pH}$ plot. Assuming that these reactions are only governed by the $\mathrm{p} K_{\mathrm{a}}$ values of the quinone, the semiquinone radical and the hydroquinone, it can be explained that with increasing $\mathrm{pH}$ the mechanism of reduction will theoretically change from ee $\left(E_{1 / 2}\right.$ is independent of $\left.\mathrm{pH}\right)$ via Hee and eHe (30 $\mathrm{mV} \mathrm{pH}^{-1}$ unit) to $\mathrm{HeHe}$, eHHe and eHeH $\left(60 \mathrm{mV} \mathrm{pH}^{-1}\right)$, respectively, followed by eHe and eeH $\left(30 \mathrm{mV} \mathrm{pH}^{-1}\right)$ and finally by ee ( $E_{1 / 2}$ independent of $\mathrm{pH}$ ), with the reverse order for the oxidation reactions. The order of $\mathrm{HeHe}$, eHHe and $\mathrm{eHeH}$ in the medium $\mathrm{pH}$ range, resulting in a slope of $60 \mathrm{mV} \mathrm{pH}{ }^{-1}$ in the $E_{1 / 2}-\mathrm{pH}$ plot, has been also suggested by Laviron [29].

The reaction pathways outlined above are general schemes only, valid in situations where no complicating factors influence the electrode process. In aqueous solvents, complications such as adsorption and pre- and post-protonation should be considered, which depend strongly on the type of electrode. It is clear from this discussion that the exact sequence of proton and electron uptake cannot be determined from the $E_{1 / 2}-\mathrm{pH}$ plot and more experimental data (e.g., obtained from spectroscopic and/or quantum mechanical studies) are required. Further, any interaction between the compound (in either the reduced or oxidized state) and the electrode (e.g., adsorption) may affect the preceding or following proton and/or electron uptake and, consequently, changes in the mechanisms presented above may take place, depending on the type of electrode and the compound. In addition, acid-base equilibria of substituents attached to the quinone function may also influence the mechanism of reduction (see below).

It is beyond the scope of this study to elucidate the exact sequence of proton and electron uptake; only substituent effects on the overall reduction of quinone to hydroquinone will be discussed here. 
Electrochemical properties of unsubstituted qutnones

The selected quinones form an appropriate group of compounds to be studied as model compounds of aziridinylquinoid and mitomycin-type antitumour agents. The unsubstituted quinones, viz., 1,4-benzoquinone (I) and 1,4-naphthoquinone (VII), can be taken as the starting structures. The $E_{1 / 2}-\mathrm{pH}$ plots obtained for both compounds are depicted in Fig. 4. The polarographic properties of I could only be examined over a limited $\mathrm{pH}$ range owing to the positive potentials at which $I$ is reduced at a DME in aqueous media. The mechanism of reduction of 1,4-naphthoquinone (VII) will be discussed in more detail, since monosubstitution has been mainly performed on this compound. The influence of a single substituent on the electrochemical properties of the quinone function could be examined in this way. Polysubstitution was carried out on 1,4-benzoquinone.

The $E_{1 / 2}-\mathrm{pH}$ plot of VII in the region from $\mathrm{pH}$ 1.5 to 9.5 is a straight line with a slope of $56 \mathrm{mV}$ $\mathrm{pH}^{-1}$. Two inflection points can be observed, one at $\mathrm{pH} \mathrm{10,} \mathrm{where} \mathrm{the} \mathrm{reduction} \mathrm{of} \mathrm{VII} \mathrm{becomes}$ independent of $\mathrm{pH}$, and one at $\mathrm{pH} 1$, where the slope decreases to $30 \mathrm{mV} \mathrm{pH}^{-1}$. It is obvious that the $\mathrm{pH}$ dependence of $56 \mathrm{mV} \mathrm{pH} \mathrm{pH}^{-1}$ indicates the transfer of two protons and two electrons. As both one-electron processes have almost equal activation energy, only one wave corresponding to a total transfer of two electrons is observed in the polarograms. The inflection point in the $E_{1 / 2}-\mathrm{pH}$ plot at $\mathrm{pH} 10$ corresponds to the $\mathrm{p} K_{\mathrm{a}}$ of the hydroquinone dianion $\left(\mathrm{p} K_{2}^{\mathrm{HQ}}\right)$. Not all compounds studied exhibit a direct change of the slope of the $E_{1 / 2}-\mathrm{pH}$ plot from $60 \mathrm{mV} \mathrm{pH}^{-1}$ to $\mathrm{pH}$ independence. Sometimes an intermediate range of $30 \mathrm{mV} \mathrm{pH}^{-1}$ can be distinguished, depending on the actual difference between $\mathrm{p} K_{1}^{\mathrm{HQ}}$ and $\mathrm{p} K_{2}^{\mathrm{HQ}}$. If these $\mathrm{p} K_{\mathrm{a}}$ values differ sufficiently (values of 9.9 and 11.4 have been reported [27]), a gradual decrease in the slope from 60 to $30 \mathrm{mV}$ $\mathrm{pH}^{-1}$ and finally to $\mathrm{pH}$ independence may be observed, provided that the chemical stability of the compound permits its polarographic analysis (see above). The inflection point in the $E_{1 / 2} \mathrm{pH}$ plot of VII observed at pH 1 might be explained by the interference of the mercury oxidation, which may have introduced a large inaccuracy in the determination of the half-wave potentials in this $\mathrm{pH}$ region. It seems unlikely that this inflection point corresponds to the $\mathrm{p} K_{2}^{\mathrm{Q}}$ value of the compound, since $\mathrm{p} K_{1}^{\mathrm{Q}}$ and $\mathrm{p} K_{2}^{\mathrm{Q}}$ values of -28 and -7 , respectively, have been suggested $[27,29]$.

The limiting current of the reduction of VII is constant over the $\mathrm{pH}$ range studied, except at $\mathrm{pH}>10$ where decomposition of the parent compound causes a decrease in its concentration and thus a decrease in the limiting current. Decomposition of quinones at alkaline $\mathrm{pH}$ is caused by the addition of $\mathrm{OH}^{-}$ions at the quinone molety and leads to the formation of, among other products, the corresponding hydroquinone [29,30]. Indeed, an oxidation wave of the hydroquinone was frequently observed in the polarograms at alkaline $\mathrm{pH}$. This type of decomposition was noticeable with many of the compounds studied. Other types of degradation processes were also observed, as will be discussed later in this section.

Electrochemical properties of substituted quinones Several effects may be induced by the introduction of substituents at the quinone function: the electron-donating or -withdrawing character of the substituent may influence the uptake of electrons by the quinone moiety and may thus cause a shift in the half-wave potential to more negative or more positive potentials, respectively, at each $\mathrm{pH}$ value of the solution; a change in the reduction mechanism may occur, mainly as a result of the presence of an additional acid-base reaction; steric effects may play a role in the reduction process, especially in the case of polysubstitution; since only small substituents are attached to the quinone moiety of the compounds examined in this study, steric effects may be less pronounced here; differences may be observed due to an increased or decreased chemical stability of the compound, sometimes leading to the formation of electroactive degradation products; hydrogen bonds may be formed between the carbonyl function (acceptor) and the substituent of interest (donor), also influencing its electrochemical properties.

In order to compare (some of) these substituent effects within this particular group of quinones, the half-wave potentials of all compounds studied 
at one particular pH are given in Table 2. For this purpose $\mathrm{pH} 7$ was selected, because the data indicate that at this $\mathrm{pH}$ virtually all compounds are reduced in a two-proton, two-electron step (except XII), without complicatıons such as wave splittıng, decomposition of the parent compound or protonation of functional groups of the compound prior to or after the quinone reduction step, which may affect the slope of the $E_{1 / 2}-\mathrm{pH}$ plot. As can be concluded from Table 2, all the quinones studied (except XII) reveal a slope of about $60 \mathrm{mV} \mathrm{pH} \mathrm{pH}^{-1}$ at $\mathrm{pH} 7.0$ and all are reduced with an overall electron transfer of approximately two. In other words, the electrode mechanisms may be regarded as comparable for all compounds studied at this $\mathrm{pH}$, which is required for a correct examination of substituent effects in organic polarography [16].

Methyl substituents. Substitution of I or VII with one methyl group results in a shift of $E_{1 / 2}$ of about $50 \mathrm{mV}$ to more negative values (compare I/II and VII/VIII). This shift, which is the result of the electron-donating properties of the methyl group, is of the same order of magnitude as reported by others [16,31]. The $E_{1 / 2}-\mathrm{pH}$ plots of II and VIII (Fig. 4) are qualitatively comparable to those of the unsubstituted quinones I and VII, respectively. The calculated slopes approach the theoretical value of $59 \mathrm{mV} \mathrm{pH}^{-1}$ for a reversible system. The reduction mechanisms of both $\mathbf{I I}$ and VIII change gradually from a pH-dependent into a $\mathrm{pH}$-independent process at alkaline $\mathrm{pH}$. The $\mathrm{p} K_{1}^{\mathrm{HQ}}$ and $\mathrm{p} K_{2}^{\mathrm{HQ}}$ values of II cannot be estimated because the number of data in the high $\mathrm{pH}$ region is too limited, owing to rapid decomposition of II. For quinone VIII, which is more stable in alkaline media, these values can be estimated to be about 11.5 and 12.5, respectively. Substitution of I with four methyl groups (yielding III) causes a shift of $E_{1 / 2}$ by $200 \mathrm{mV}$ to more negative values, which is the sum of the contribution of four separate methyl groups. As quinone III is less subject to degradation processes in alkaline media, it was possible to study this compound over a wide $\mathrm{pH}$ range. The inflection point at $\mathrm{pH} 12$ corresponds to the $\mathrm{p} K_{1}^{\mathrm{HQ}}$ value of the hydroquinone monoanion of III, which is in good agreement with the value reported by Flaig et al. [31]. Whether the inflection point in strongly acidic media corresponds to a $\mathrm{p} K_{\mathrm{a}}$ value of the quinoid form is very doubtful, as stated earlier.

Amino substituents. The influence of one or two amino groups on the reduction mechanism of these quinones was studied with IX and IV, 2-amino1,4-naphthoquinone and 2,5-diamino-1,4-benzoquinone, respectively. Each amino function causes a shift of $E_{1 / 2}$ at $\mathrm{pH} 7.0$ of ca. $225 \mathrm{mV}$ to more negative potentials, as compared with the unsubstituted analogue VII and I, respectively. A mesomeric interaction between the lone pair on nitrogen and the quinone moiety is responsible for the electron-donating character of the amino group, which explains these shifts in $E_{1 / 2}$ [32]. In addition, tautomerization may take place (Fig. 7), leading to the formation of a quinoneimine structure. The presence of a tautomeric equilibrium, however, has not been observed in the polarographic curves of IV and IX. Hydrogen bonds between the amino and carbonyl groups of the quinone moiety may stabilize the quinoid form and may thus be partly responsible for the negative shift of $E_{1 / 2}$ also [33].

At neutral $\mathrm{pH}$ both IV and IX undergo the two-proton, two-electron reduction discussed before, as can be concluded from the slopes of the $E_{1 / 2}-\mathrm{pH}$ plots. The change in reduction mechanism with increasing $\mathrm{pH}$, as observed for the quinones discussed previously, can be distınguished for these aminoquinones also. How-

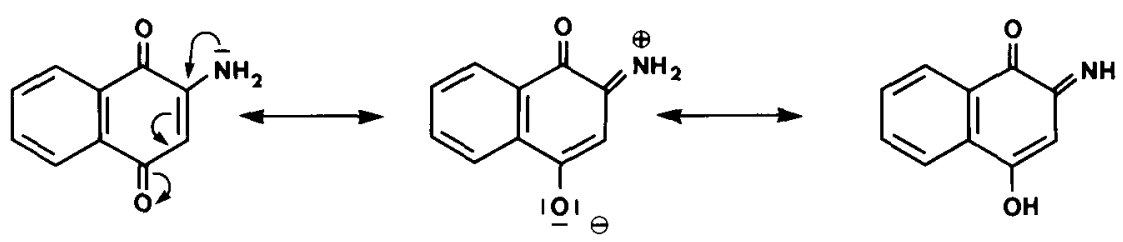

Fig. 7 Tautomerization of amınoquinones, e g, of 2-amino-1,4-naphthoquinone (IX) 
ever, there is a new phenomenon that can be observed at alkaline $\mathrm{pH}$, viz. a pH-dependent decomposition of the parent compound into one or two less easily reducible compounds. This behaviour can be attributed to the alkaline hydrolysis of the amino function, as has been reported for similar quinones [34]. Equal $E_{1 / 2}$ values of the decomposition products and of pure 2-hydroxy1,4-naphthoquinone (XII) and 2,5-dihydroxy-1,4benzoquinone (Aldrich Europe) were obtained, which is an indication of the identity of the degradation products formed.

A second phenomenon, new in comparison with what has been discussed up to now, is evident in acidic media, viz., an increase in the slope of the $E_{1 / 2}-\mathrm{pH}$ plot from approx. 60 to approx. 90 and/or $120 \mathrm{mV} / \mathrm{pH}$-unit (Fig. 4). For the monoamino analogue IX the slope increases to $86 \mathrm{mV}$ $\mathrm{pH}^{-1}$ at the inflection point at $\mathrm{pH} 4$. The $E_{1 / 2}-\mathrm{pH}$ plot of IV exhibits two inflection points with decreasing $\mathrm{pH}$ : at $\mathrm{pH} 6.5$ the slope increases to 84 $\mathrm{mV} \mathrm{pH}{ }^{-1}$ and at $\mathrm{pH} 3$ to $119 \mathrm{mV} \mathrm{pH}^{-1}$. Slopes of

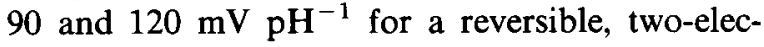
tron reduction process mean the consumption of three and four protons, respectively, during the reduction, so the product must be the mono- and diprotonated hydroquinone, respectively (Schemes 2 and 3, Fig. 8). The inflection point observed at $\mathrm{pH} 4$ in the $E_{1 / 2}-\mathrm{pH}$ plot of IX must therefore correspond to the $\mathrm{p} K_{\mathrm{a}}$ of the protonated amino function of the hydroquinone, i.e., $\mathrm{p} K_{3}^{\mathrm{HQ}}$. This compares well with the value of 4.04 reported for 2-amino-1,4-napthohydroquinone [35]. The $\mathrm{p} K_{\mathrm{a}}$ value of the amino function of the quinone $\left(\mathrm{p} K_{3}^{\mathrm{Q}}\right)$ was determined spectrophotometrically and was found to be -1.0 , which clearly demonstrates the strongly electron-withdrawing character of the quinone moiety. Reduction to the more electrondonating hydroquinone abolishes this effect and consequently the amino function is more easily protonated. In analogy, the inflection points observed in the $E_{1 / 2}-\mathrm{pH}$ plot of 2,5-diamino-1,4benzoquinone (IV) correspond to the $\mathrm{p} K_{\mathrm{a}}$ values of the two amino functions of the hydroquinone $\left(\mathrm{p} K_{4}^{\mathrm{HQ}}=6.5, \mathrm{p} K_{3}^{\mathrm{HQ}}=3\right)$. The theoretical decrease in the slope from 90 to 60 (one amino function, Fig. 8a) and from 120 to 90 to 60 (two amino functions, Fig. $8 \mathrm{~b}$ ) on decreasing the $\mathrm{pH}$ as the $\mathrm{pH}$ becomes lower than $\mathrm{p} K_{3}^{\mathrm{Q}}$ (and $\mathrm{p} K_{4}^{\mathrm{Q}}$ ) cannot be observed experimentally, owing to the low $\mathrm{p} K_{\mathrm{a}}$ values and the interference because of the oxidation of mercury in acidic media.

The influence of mono- and dimethylation of the amino function on the electrochemical properties of the aminoquinone was studied with V, VI, $\mathbf{X}$ and $\mathbf{X I}$ in comparison with the non-methylated aminoquinones IV and IX. In general, the $E_{1 / 2}-\mathrm{pH}$ plots of all these compounds show patterns similar to those of IV and IX (Fig. 4). Decomposition of the parent compound at high $\mathrm{pH}$ is observed for
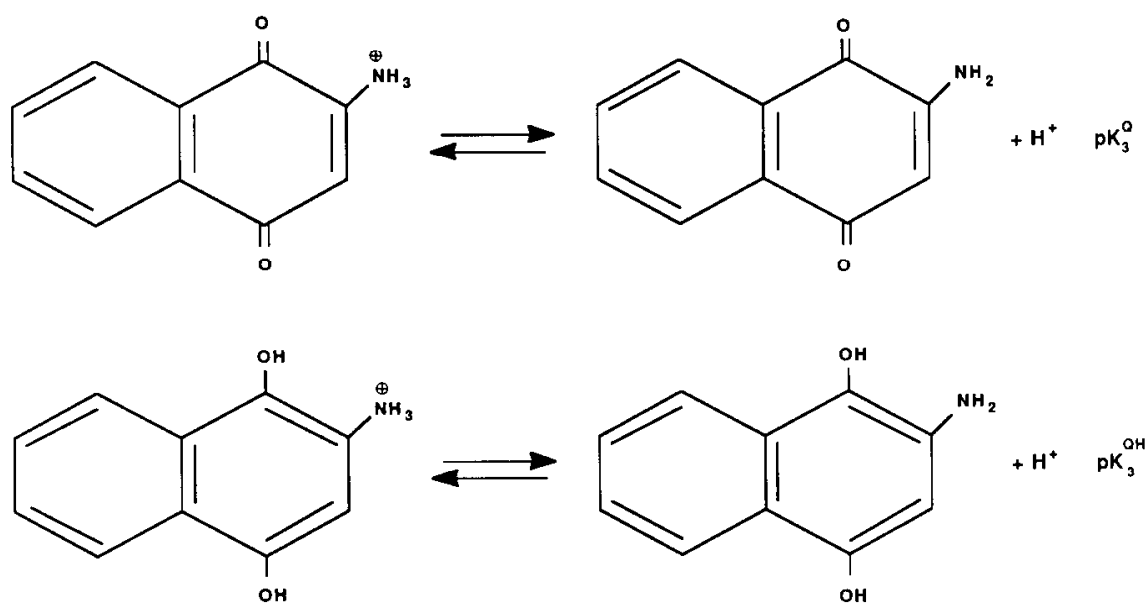

Scheme 2 Acıd-base equilibria during the reduction of monoamınoquinones 

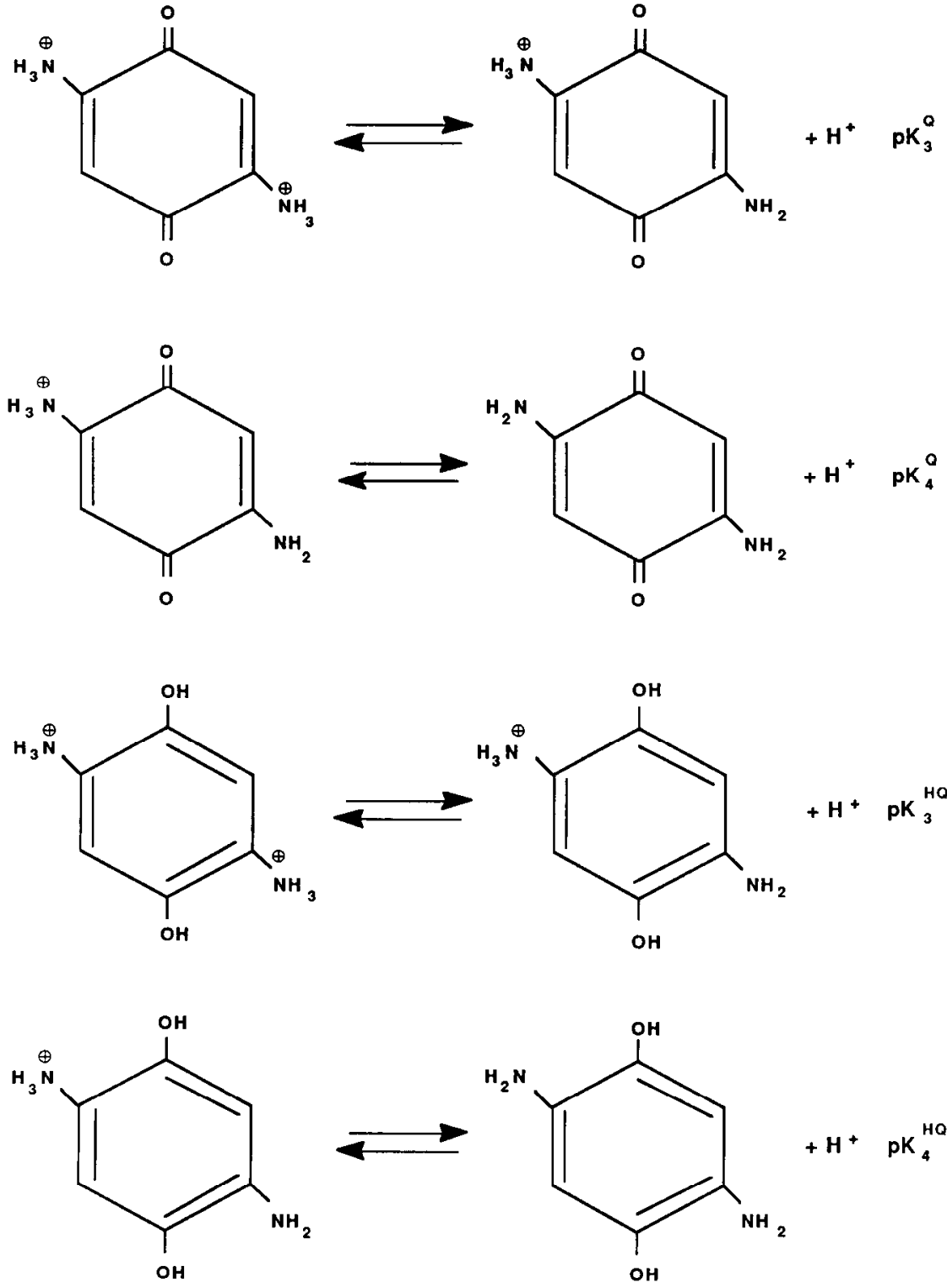

Scheme 3 Acid-base equilibria during the reduction of diamınoquinones

both the mono- and the dimethylaminoquinone, leading to the formation of the corresponding hydroquinone. As observed with the aminoquinones, the methylated derivatives also show an increasing slope of the $E_{1 / 2}-\mathrm{pH}$ plot on decreasing the $\mathrm{pH}$. Depending on whether the compound is substituted with one or two methylamino functions, the slope increases to about 90 or $120 \mathrm{mV}$
$\mathrm{pH}^{-1}$. Protonation of the mitrogen atom(s) of the reduced form is responsible for this behaviour, as outlined above. Similar observations have been reported by Huntington and Davis [36] and Cameron et al. [37]. The $\mathrm{p} K_{3}^{\mathrm{HQ}}$ value of $\mathbf{X}$ can be estimated to be about 5.5 , whereas $\mathrm{p} K_{3}^{\mathrm{Q}}$ was determined spectrophotometrically to be -0.5 . Both values are higher than the values obtained 

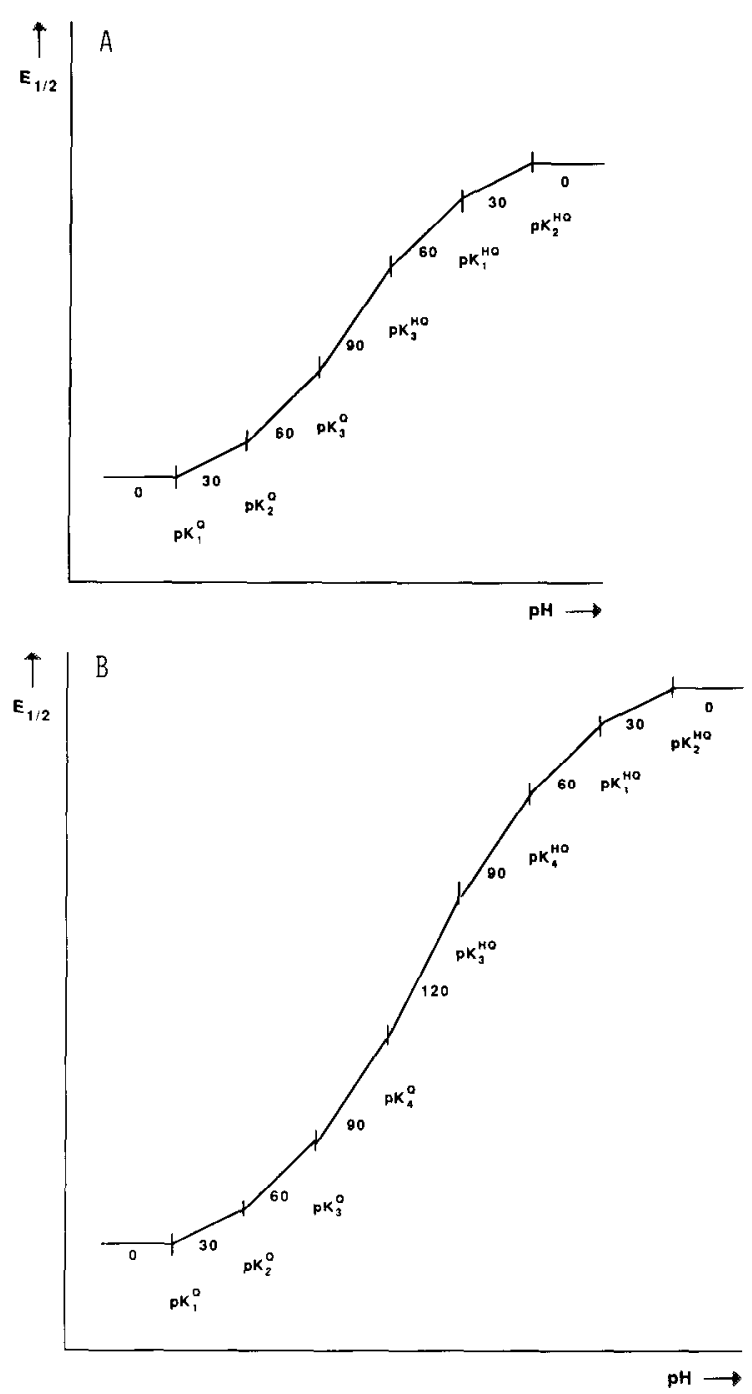

Fig 8 Hypothetical $E_{1 / 2}-\mathrm{pH}$ plots for the two-electron reduction wave of quinones having (A) one and (B) two amıno functions attached to the quinone function Inflection points at acidic $\mathrm{pH}$ correspond to $\mathrm{p} K_{\mathrm{a}}$ values of the quinone moiety, those at alkalıne $\mathrm{pH}$ to the $\mathrm{p} K_{\mathrm{a}}$ values of the hydroquinone and those in the intermediate $\mathrm{pH}$ range to the $\mathrm{p} K_{\mathrm{a}}$ values of the amino functions of the quinone and the hydroquinone (see Schemes 2 and 3)

for the corresponding amino derivative (4.0 and -1.0 , respectively), which is probably related to the electron-donating influence of the methyl group. For XI a $\mathrm{p} K_{3}^{\mathrm{HQ}}$ value of ca. 6 can be determined from the $E_{1 / 2}-\mathrm{pH}$ plot, whereas in the quinoid form a $\mathrm{pK}_{3}^{\mathrm{Q}}$ value of -0.1 was de- termined. For XIII these values are 3.0 and -1.0 , respectively. From the $E_{1 / 2}-\mathrm{pH}$ plots of the bisaminated benzoquinones, $\mathrm{pK}{ }^{\mathrm{HQ}}$ values of 6.5 and 3 were determined for the non-methylated aminohydroquinone IV, 6 and 4 for the monomethylated analogue $\mathrm{V}$ and one overall $\mathrm{p} K$ of ca. 6 for the dimethylated aminoquinone VI, which indicates simultaneous protonation of both amino functions. No clear electronic effects on $\mathrm{p} K^{\mathrm{HQ}}$ can be observed, possibly owing to the formation of hydrogen bonds between the hydroxyl group (donor) and the amıno substituent (acceptor), which may lower the $\mathrm{p} K^{\mathrm{HQ}}$ value.

Both a mesomeric interaction between the lone pair on nitrogen and the quinone function and the ability to form hydrogen bonds (between the amino function and the carbonyl group of the quinone) may be held partly responsible for the shift of the half-wave potentral of the quinone reduction process to more negative values on introduction of an amino, a methylamino and a dimethylamino function. Monomethylation of the amino group results in a shift of $E_{1 / 2}$ to more negative values, probably caused by an increased electron-donating character of the substituent in comparison with a non-methylated amino function. However, introduction of the second methyl group results in a tertiary amino function, which has lost the possibility of both hydrogen bond formation and tautomerization. As a result, less stabilization of the quinoid form, less mesomeric interaction with the quinone nucleus, a smaller electron-donating character than that of the monomethylated amino group and, consequently, a shift of $E_{1 / 2}$ to less negative values is observed. Extension of the dimethylamino group to a pyrrolidinyl function increases the electron-donating effect of the substituent, owing to good overlapping of the quinone nucleus by the lone pair.

Hydroxy substituents. Substitution of 1,4-naphthoquinone (VII) by a hydroxy group at postion 2 of the quinone moiety, resulting in XII, causes a significant change in the reduction mechanism, as can be observed in the $E_{1 / 2}-\mathrm{pH}$ plots for the two compounds (Fig. 4). Responsible for this phenomenon is the dissociation of the 2-hydroxy group. This group has $\mathrm{p} K_{3}^{\mathrm{Q}} \approx 4$, as determined by titratıon. Consequently, at $\mathrm{pH}<\mathrm{p} K_{3}^{\mathrm{Q}}$, XII is reduced 
in a two-proton, two-electron step, as indicated by the slope of the $E_{1 / 2}-\mathrm{pH}$ plot of $55 \mathrm{mV} \mathrm{pH}^{-1}$. However, at $\mathrm{pH}>\mathrm{p} K_{3}^{\mathrm{Q}}$ the deprotonated form of XII (the anion) predominates in the bulk of the solution. Reduction of the anion in a normal two-proton, two-electron process will now be immediately followed by protonation of the deprotonated 2-hydroxy group, since $\mathrm{p} K_{3}^{\mathrm{HQ}}$ will be much higher than $\mathrm{p} K_{3}^{\mathrm{Q}}$, as a result of the electron-donating character of the hydroquinone moiety, as compared with the electron-withdrawing quinone. Hence the overall effect in the electrode process is a transfer of three protons and two electrons, which results in a slope of the $E_{1 / 2}-\mathrm{pH}$ plot of $90 \mathrm{mV} \mathrm{pH}^{-1}$. At $\mathrm{pH}>10$ the slope decreases owing to one of the $\mathrm{p} K^{\mathrm{HQ}}$ values of the hydroxy groups in the hydroquinone of XII being exceeded. A similar $\mathrm{pH}$ dependence of $E_{1 / 2}$ of this compound was reported by Flaig et al. [31].

In conclusion, the data presented provide much information on the influence of individual substituents and the role of acid-base reactions in the electrochemistry of 1,4-naphtho- and 1,4-benzoquinones. The compounds examined here can be considered to be model compounds of many quinoid antitumour agents. The substituents studied are very common and frequently form an essential part of such types of cytostatics, since they affect directly the electrochemical activation steps of the quinone. It is is clear that the presence of simple functions in the molecular structure of the compound may lead to significant changes in electrochemical behaviour. These changes may, for instance, be the result of an increased electron density of the quinone moiety, caused by the electronic character of the substituent(s), as can be observed with, e.g., alkyl substitution. However, complications may arise: pre- and post-protonation of substituents, hydrogen bond formation and tautomerization reactions may occur and may strongly influence the ease of reduction of the compound, as reflected by a shift in the half-wave potential or a change in the $\mathrm{pH}$ dependence of $E_{1 / 2}$. In addition, steric interactions between the quinone moiety and substituents may occur. Owing to this complexity the reduction mechanisms of quinoid compounds have to be elucidated first, before the influence of quinone substituents can be examined properly. The substituent effects observed in the present series of quinones have been explained only qualitatively up to now. The quantitative structure-electrochemistry relationships of a series of 92 quinones will be reported later.

The alkylating parts of aziridinylquinoid antitumour agents, viz., the aziridinyl rings, are also amino functions. These rings can be considered to be dimethylamino functions, closed to a cyclic system. The framework of the mitomycins, i.e., the mitosane skeleton, can be considered to be a pyrrolidinyl function, closed to a cyclic system. The information obtained in this study will be used in subsequent papers on the aqueous electrochemstry of aziridinylquinones and mitomycin $\mathrm{C}$ and has been of benefit in the elucidation of their reduction mechanisms.

\section{REFERENCES}

1 N.R Bachur, S L Gordon and MV Gee, Cancer Res. 38 (1978) 1745.

2 H. Kappus, Biochem. Pharmacol., 35 (1986) 1.

3 K A. Kennedy, B.A Teicher, S Rockwell and A C Sartorell, in A C Sartorell (Ed), Molecular Actions and Targets for Cancer Chemotherapeutic Agents, Academic Press, New York, 1981, pp 85-101

4 A.C. Sartonelli, Adv. Enzyme Regul., 20 (1982) 233.

5 R.J Driebergen, J.J M. Holthuis, A Hulshoff, S J Postma-Kelder, W. Verboom, DN Reinhoudt and $P$ Lelieveld, Antıcancer Res , 6 (1986) 605

6 R.J Driebergen, Dissertation, University of Utrecht, 1987

7 J. Lapuscinskı and Z. Darzynkıewıcz, Bıochem. Pharmacol, 34 (1985) 4203.

8 H.D.H Showalter, D.W Fry, W R. Leopold, J W Lown, J.A Plambeck and K Reszka, Anti-Cancer Drug Design, 1 (1986) 73.

9 R Andreolı, G. Battıstuzzı Gaviolı, G. Grandı, L. Benedettı and A. Rastell,, J. Electroanal. Chem., 108 (1980) 77.

10 G.E Adams, J.R Flockhardt, C E. Smithen, I.J Stratford, P. Wardman and M.E. Watts, Radiat Res, 67 (1976) 9

11 B S. Iyengar, S M. Samu, S E. Tarnow, W.A Remers, W T Bradner and J.E. Schurig, J. Med Chem, 26 (1983) 1453

12 B S Iyengar, H.-J. Lın, J Cheng, W.A Remers and W T Bradner, J. Med. Chem, 24 (1981) 975

13 B S. Iyengar, S.M Sam, W A. Remers, W T Bradner and J.E Schurig, J Med Chem, 26 (1983) 16.

14 S.M Samı, B.S Iyengar, S E Tarnow, W.A Remers, W T Bradner and J.E. Schung, J Med Chem., 27 (1984) 701. 
15 J. den Hartıgh, Dissertation. University of Utrecht, 1986.

16 P. Zuman, in P. Zuman (Ed.), Substituent Effects in Organic Polarography, Plenum, New York, 1967, pp 1-41.

17 H W. Morre, H.R. Shelden and D F Shellhamer, J. Org. Chem., 34 (1969) 1999.

18 Y Garreau, Bull. Soc. Chum. Fr., (1950) 501

19 R Baltzly and E. Lorz, J. Am Chem. Soc, 70 (1948) 861.

20 L.F. Fieser and J.L. Hartwell, J. Am. Chem. Soc., 57 (1935) 1482

21 U S. Rubber, Belf. Pat., 614136, 1962; Chem Abstr., 57 (1963) 15031.

22 S.N Fallıng and H Rapoport, J. Org Chem, 45 (1980) 1260.

23 L. Meites, in L. Meites (Ed.), Polarographic Techniques, Interscience, New York, 1965, p. 87.

24 P. Zuman and I.M. Kolthoff, in P Zuman and I.M. Kolthoff (Eds.), Progress in Polarography, Vol 2, Interscience, New York, 1962, pp. 583-600

25 P J. Elving and J.T. Leone, J. Am. Chem. Soc., 80 (1958) 1021

26 I.M Kolthoff, in I.M. Kolthoff and J.J Lingane (Eds.), Polarography, Interscience, New York, 1952, p 377.
27 J Q Chambers, in S Patal and Z. Rappoport (Eds.). The Chemistry of Quinonord Compounds, Vol 2, Wiley, Chichester, 1988, pp. 719-757

28 G Dryhurst, K.M. Kadısh, F Scheller and R Renneberg, in (G Dryhurst, Ed.), Biological Electrochemistry, Academic, New York, 1982, pp. 1-115

29 E. Laviron, J. Electroanal. Chem., 164 (1984) 213

30 H. Erdtman and M. Granath, Acta Chem. Scand, 8 (1954) 811

31 W. Flaig, H. Beutelspacher, H. Riemer and E. Kaelke, Justus Liebigs Ann. Chem, 719 (1968) 96.

32 S. Dühne, J Rauft and H Paul, Tetrahedron Lett, (1964) 3355 .

33 J.L. Huntıngton and D.G. Davis, J. Magn. Reson., 3 (1970) 456.

34 C.E. Dalgiesh, J Am Chem. Soc, 71 (1949) 1697.

35 O. Fieser, J. Am. Chem Soc., 56 (1934) 1565

36 J.L. Huntıngton and D.G. Davis, J Electrochem Soc, 118 (1971) 57

37 D W Cameron, R.G F. Giles and M H Pay, Tetrahedron Lett., (1970) 2049. 